\title{
К ВОПРОСУ О ФУНКЦИОНАЛЬНОЙ ОРГАНИЗАЦИИ ЛЕКСИЧЕСКОГО МИНИМУМА НА ОСНОВЕ МЕТОДА КОММУНИКАТИВНЫХ ЗАДАЧ
}

\author{
SOME ASPECTS OF THE FUNCTIONAL ORGANIZATION \\ OF THE LEXICAL MINIMUM IN REFERENCE \\ TO TASK-BASED LANGUAGE TEACHING
}

JAKUB WALCZAK, DOROTA DRUŻYŁOWSKA

\begin{abstract}
AвSTRAст. This paper is the result of the work on the lexical minimum of Russian language for bachelors of Russian philology within the context of Task-based Language Teaching method. The text provides a definition of the lexical minimum, presents the main principles of the Task-based Language Teaching. The main part of the article is devoted to the presentation of the principles of selection and organization of the language material included in the proposed lexical minimum.
\end{abstract}

Keywords: lexical minimum, Russian as Foreign Language, Task-based Language Teaching Jakub Walczak, Uniwersytet Wrocławski, Wrocław - Polska, jakub.walczak@uwr.edu.pl ORCID ID: 0000-0002-4714-1762

Dorota Drużyłowska, Uniwersytet Wrocławski, Wrocław - Polska, dorota.druzylowska@uwr.edu.pl

ORCID ID: 0000-0002-1246-406X

Настоящая статья посвящена презентации лексического минимума [cм. Drużyłowska, Walczak 2017], разработанного в рамках проекта Теоретические основы определения лексического минимума для бакалавров русской филологии (в Институте славянской филологии Вроцлавского университета). В статье обсуждаются следующие вопросы:

1) предпосылки разработки лексического минимума;

2) основные принципы метода Task-based Language Teaching;

3) принципы отбора и организации языкового материала.

Теоретической основой разработки настоящего лексического минимума стала дефиниция, предложенная Анатолием Щукиным и Ельханом Азимовым, согласно которой лексический минимум представляет собой 
лексические единицы, которые должны быть усвоены учащимся за определенный промежуток учебного времени. Количественный и качественный состав лексического минимума зависит от целей обучения, этапа обучения и количества учебных часов, отводимых для изучения языка. В методической литературе описаны следующие принципы отбора лексического минимума: статистический (критериями отбора слов являются частотность, распространенность, употребительность, необходимость или наличность), методический (учитывающий этап обучения, сферу и тему общения), лингвистический (сочетаемость слова, словообразовательная ценность, стилистическая неограниченность) [Азимов, Щукин 2009: 121].

Вышеприведенному определению лексического минимума предшествовало, как справедливо замечает Елена Маркина, очень широкое и, соответственно, недостаточно четкое понимание данного термина. Еще в 60-80-е гг. лексический минимум отождествлялся с любым списком слов (часто без перевода и комментариев), которыми следовало овладеть на данном этапе обучения, одноязычными и двуязычными учебными словарями, приложениями к учебникам и др. [Маркина 2011: 248].

Опираясь на приведенную выше дефиницию, авторы определили ключевые аспекты разрабатываемого минимума, в том числе цели (подготовка филологов-русистов), время (3 года), этап обучения (бакалавриат, филологическое образование), количество учебных часов (аудиторные часы, отведенные для занятий по РКИ в программе обучения) и др.; они подробно рассматриваются в дальнейшей части текста.

Решение разработать лексический минимум было обусловлено рядом объективных причин. Главной задачей было определение объема лексики, активное овладение которой необходимо для сдачи итогового экзамена по русскому языку студентами третьего курса отделения русской филологии Вроцлавского университета. В связи с тем, что русский язык преподается далеко не во всех польских школах, на русскую филологию поступают абитуриенты преимущественно изучающие русский язык „с нуля”. В течение трех лет бакалавриата студенты должны достичь уровня В2, в течение следующих двух лет магистратуры - C1.

Лексический минимум должен помочь подготовить студентов к выходу на рынок труда: в настоящее время - это в основном международные компании, корпорации и др. Надо иметь в виду, что только немногие выпускники русской филологии работают учителями русского языка, как сорок лет назад.

Важной причиной создания минимума являлся тот факт, что минимумы, разработанные в России для широкого круга учащихся, т.е. представителей разных национальностей, носителей языков в разной степени близких русскому языку, не являются достаточными для поляков, изучающих русский, особенно на начальном этапе обучения. Лексический минимум 
предназначен для польскоговорящих студентов, относительно быстро овладевающих русской лексикой за счет близкородственности языков. В связи с этим авторы старались включить в него, в первую очередь, слова в типичных словосочетаниях, нежели отдельные списки слов. Слова снабжались грамматическим комментарием только в случаях межъязыковой интерференции, например, при несовпадении родов: метод $м$ - metoda ж; проблема ж - problem м и др., или при разнице в управлении, например: гордиться кем - bус́ duтпут z kogo, ждать кого - сzеkас́ na kogo, звонить кому $d z w o n i c ́$ do kogo, или при несовпадении категории числа: дверь ед. ч. - drzwi мн. ч. и др. Комментарии подобного типа не применяются в случае совпадения определенных языковых явлений, в связи с тем, что представляется оправданным положиться на языковую интуицию учащихся (например, не определяется род существительных мама - тата, браm - brat, окно - okno и др.). Во всех словах обозначено ударение, представляющее собой значительную проблему при овладении русским языком.

В основу принципа идеографической организации материала положена программа обучения на 1-3 курсах русской филологии в Институте славянской филологии Вроцлавского университета, включающая 24 темы: знакомство, семья, дом, свободное время, хобби, трудоустройство, еда, покупки, одежда и др. [см. van Ek, Trim 1991: 59-81]. В основу организации отдельных тем положены возможные коммуникативные ситуации, в которых могут оказаться студенты или выпускники: в вузе, в библиотеке, в магазине, в общежитии, во время путешествия, на границе, в гостинице и т.Д.

Таким образом, центром организации материала является коммуникативная задача, непосредственно связанная с лингводидактическим методом Task-based Language Teaching.

Упомянутое понятие коммуникативной задачи, обусловленное ситуационным контекстом, реализуется в языковом действии, цель которого - достижение уровня эффективной коммуникации в различных сферах общественной жизни. Другими словами, языковое действие (построение речевых текстов в устной и письменной форме) тесно связано с попыткой решить какую-либо проблему (задачу), выполнить обязательство, например, составить приветствие при встрече, обращение с выражением пожеланий, дружелюбия, расположения к кому-либо или же приглашение, высказать просьбу, предложение сделать что-либо, предложить провести совместно время (элементарный и базовый уровни А1-2); заказать еду в ресторане или определить состояние своего здоровья (B1-B2), принять активное участие в дискуссии (С1-С2) и т. д.

В свете вышесказанного встал вопрос о практической направленности лексического минимума. Авторы выдвинули предположение, что 
минимум должен быть функциональным и ориентированным на реальные потребности пользователей, связанные с общением на русском языке; следует также подчеркнуть, что в пособии дается современный лексический материал, который подобран в соответствии с тематикой, связанной с реальной жизнью человека и его бытом. Во многих учебниках по иностранным языкам, в тематических словарях, лексических минимумах представлена устаревшая лексика (например: изветной телевизор, чернильница и чернила и т. д.), а иллюстративный материал в виде словосочетаний и выражений - если вообще выступает - прежде всего принадлежит книжным стилям, которые очень редко встречаются в узусе обиходного общения, например: предъявить билет (в троллейбусе) вместо показать билет.

Полезными в этом вопросе оказались теоретические принципы Taskbased Language Teaching - метода обучения, основанного на задачах, которые существуют в современной западной лингводидактике уже около двадцати лет, но редко применяются в методике преподавания РКИ. Стоит отметить, что этот подход в целом соответствует теоретическим предпосылкам, описанным в европейской системе преподавания иностранных языков CEFR [См. Coste, North, Sheils, Trim 2003]. Английский методист Дэвид Нунан во введении к своей работе Task-based Language Teaching (2004) кратко охарактеризовал этот метод, отметив следующие исходные положения:

- необходимость отбора языкового материала;

- интеракция на изучаемом иностранном языке;

- введение подлинных текстов в процесс обучения иностранному языку;

- учет личного опыта учащихся, в качестве важного элемента обучения в классе;

- преподавание языка, используемого вне аудитории (в реальных жизненных ситуациях) [Nunan 2004: 1].

Авторы метода TBLT предлагают определенную схему - сценарий урока. Если применить такой сценарий на практике, лексический минимум будет необходим на первом этапе задачи (Pre-task activity), который представляет собой введение в тему, попытку заинтересовать студентов и одновременно предоставление необходимых для выполнения основной задачи слов и фраз [Willis 1996: 42-51]. Следующий этап - это Task Cycle: цикл выполнения задачи и представление результатов в такой форме, которая принята учителем и учениками (Task - Planning - Report) [Willis 1996: 52-65]; в конще урока следует анализ языковых проблем, с которыми столкнулись студенты, выполняя задание (Language focus) [Willis 1996: 100-115].

Иллюстрацией, наглядно поясняющей модель такого урока, может стать ситуация, когда студент на занятиях или вне аудитории будет 
пользоваться различными услугами или просто делать покупки. Лексический минимум в предлагаемой форме должен „обеспечить” студентов лексикой, необходимой для того, чтобы решить задачу: отправиться в магазин, столовую, в пункт печати или хостел, найти туда дорогу, выбрать наиболее подходящий вид транспорта, купить билет и т.д. На следующем этапе следует установить контакт с продавцом, сделать правильный выбор, обсудить его с партнером и т.д. и, наконец, оплатить покупки и услуги, выразить благодарность и попрощаться с продавцом.

В дальнейшей части статьи приводятся примерные фрагменты минимума. Студентам предлагается следующее задание: „Представь себе, что находишься в Петербурге на языковых курсах; тебе надо выполнить домашнее задание. Сходи и запишись в городскую библиотеку, узнай, как оформляется заказ книг, какие книги тебе выдадут на дом, какими можешь пользоваться в читальном зале?"

Итак, раздел Библиотека. Книга. Пресса построен следующим образом:

1-й этап. Как записаться в библиотеку:

библиоте́ка biblioteka

записа́ться в $\sim$ у zapisać się do $\sim$ i

Подскажи́те, пожа́луйста, где мо́жно записа́ться в библиоте́ку? Przepraszam, gdzie mogę zapisać się do biblioteki?

занима́тся в $\sim$ e uczyć się $\mathrm{w} \sim$ ce

по́льзоваться ой korzystać z biblioteki

находи́ть/найти́ кни́ги в е znajdować / znaleźć książki w ce

офо́рмить чита́тельский биле́т wyrobić kartę biblioteczną

2-й этап. Как пользоваться библиотекой:

чита́льный зал czytelnia

дежу́рный по за́лу dyżurny

предъяви́ть докуме́нт (па́спорт, студе́нческий [биле́т], чита́тельский биле́т) okazać dokument (paszport, legitymację [studencką], kartę biblioteczną)

запо́лнить, офо́рмить бланк, зая́вку, тре́бование, зака́з wypełnić rewers

абонеме́нт wypożyczalnia

брать/взять кни́ги на́ дом wуроżyczać książki

ви́ддать/выдава́ть кому-н. кни́ги на́ дом wypożyczać komuś książki

продлева́ть/продли́ть срок przedłużyć termin zwrotu

кни́га на рука́x książka jest wypożyczona

сдава́ть/сдать кни́ги zwracać/zwrócić książki

возвраща́ть кни́ги в устано́вленные сро́ки zwracać książki w terminie

уте́ря кни́ги zgubienie książki

наруше́ние пра́вил по́льзования библиоте́кой naruszenie zasad korzystania z biblioteki пла́та за по́льзование литерату́рой сверх устано́вленного сро́ка kara za przetrzymanie książek 
3-й этап. Как найти нужные материалы в библиотеке:

рабо́та с катало́гом praca z katalogiem

найти́ кни́гу в катало́ге znaleźć książkę w katalogu

по́иск книг wyszukiwanie książek

вы́ххдные да́нные dane bibliograficzne

назва́ние кни́ги tytuł książki

а́втор кни́ги autor książki

шифр sygnatura

найти́ кни́гу по назва́нию znaleźć książkę po tytule

библиогра́фия, спи́сок литерату́ры bibliografia

офо́рмить $\sim$ ию $\sim$ zrobić $\sim$ ̨

Материал организован таким образом, что лексемы подаются не просто в виде списка слов, но в типичных словосочетаниях; иногда вводятся целые предложения, представляющие собой своего рода стереотипные выражения или обязательные для данной ситуации речевые клише, полезные для обучаемого.

Подводя итоги вышесказанному, следует отметить, что благодаря функциональной организации лексического минимума возможно достижение поставленных целей:

1. предоставить учащимся лексику, необходимую для решения определенных речевых задач;

2. организовать лексический материал с учетом иерархического характера значимости слов с точки зрения коммуникации;

3. значительно повысить эффективность обучения.

Предлагаемое учебное пособие Нy, ıадно! Minimum leksykalne jezyka rosyjskiego dla poziomu średnio zaawansowanego, несомненно, помогает определить лексическую базу для средне-продвинутого уровня владения русским языком, хотя и не может заменить собой более обширные лексикографические источники или учебники в ходе учебного процесса.

\section{Библиография}

Азимов Э. Г., Щукин А. Н. 2009. Новый словарь методических терминов и понятий (теория и практика обучения языкам), Москва: Икар.

Андрюшина Н. П. [et al.] 2011. Лексический минимум по русскому языку как иностранному. Базовыи уровенъ. Общее владение, Санкт-Петербург: Златоуст.

Андрюшина Н. П. [et al.] 2012. Лексический минимум по русскому языку как иностранному. Элементарный уровень. Общее владение, Санкт-Петербург: Златоуст.

Клобукова Л. П. [et al.] 2014. Лексический минимум по русскому языку как иностранному. Второй сертификационный уровенъ. Общее владение, Санкт-Петербург: Златоуст. 
Маркина Е. И. 2011. О соотнотении понятий „лексический минимум"и "учебный словарь” в методике преподавания русского языка как иностранного, „Известия Российского государственного педагогического университета им. А. И. Герцена", № 129, c. $247-250$.

Норейко Л. Н. [et al.] 2013. Лексический минимум по русскому языку как иностранному. Первый сертификационный уровень. Общее владение, Санкт-Петербург: Златоуст.

Coste D., North B., Sheils J., Trim J. 2003. Europejski system opisu kształcenia językowego: uczenie sie, nauczanie, ocenianie, tłum. W. Martyniuk, Warszawa: Wydawnictwo CODN.

Drużyłowska D., Walczak J. 2017. Hy, ıаднo! Minimum leksykalne języka rosyjskiego dla poziomu średnio zaawansowanego, Kraków: Universitas.

Ek J. A. van, Trim J. L. M. 1991. Threshold 1990, Cambridge: Cambridge University Press.

Ellis R. 2003. Task-based Language Learning and Teaching, Oxford: Oxford University Press.

Janowska I. 2011. Podejście zadaniowe do nauczania i uczenia się języków obcych, Kraków: Universitas.

Nunan D. 2004. Task-based Language Teaching, Cambridge: Cambridge University Press.

Richards J. C., Rodgers T. S. 2014. Approaches and Methods in Language Teaching, Cambridge: Cambridge University Press.

Seretny A. 2011. Kompetencja leksykalna uczacych sięjęzyka polskiego jako obcego w świetle badań ilościowych, Kraków: Wydawnictwo Uniwersytetu Jagiellońskiego.

Willis J. 1996. A Framework for Task-based Learning, Harlow: Longman. 
